\title{
The long-term economic impacts of arthritis through lost productive life years: results from an Australian microsimulation model
}

Deborah Schofield ${ }^{1}$, Michelle Cunich ${ }^{2^{*}}$ (D), Rupendra N. Shrestha', Robert Tanton ${ }^{3}$, Lennert Veerman ${ }^{4,6}$, Simon Kelly ${ }^{3}$ and Megan E. Passey ${ }^{5}$

\begin{abstract}
Background: While the direct (medical) costs of arthritis are regularly reported in cost of illness studies, the 'true' cost to indivdiuals and goverment requires the calculation of the indirect costs as well including lost productivity due to ill-health.

Methods: Respondents aged 45-64 in the ABS Survey of Disability, Ageing and Carers 2003, 2009 formed the base population. We projected the indirect costs of arthritis using Health\&WealthMOD2030 - Australia's first microsimulation model on the long-term impacts of ill-health in older workers - which incorporated outputs from established microsimulation models (STINMOD and APPSIM), population and labour force projections from Treasury, and chronic conditions trends for Australia. All costs of arthritis were expressed in real 2013 Australian dollars, adjusted for inflation over time.

Results: We estimated there are 54,000 people aged 45-64 with lost PLYS due to arthritis in 2015, increasing to 61,000 in 2030 (13\% increase). In 2015, people with lost PLYs are estimated to receive AU\$706.12 less in total income and AU\$311.67 more in welfare payments per week than full-time workers without arthritis, and pay no income tax on average. National costs include an estimated loss of AU\$1.5 billion in annual income in 2015, increasing to AU\$2.4 billion in 2030 (59\% increase). Lost annual taxation revenue was projected to increase from AU\$0.4 billion in 2015 to $\$ 0.5$ billion in 2030 (56\% increase). We projected a loss in GDP of AU\$6.2 billion in 2015, increasing to AU\$8.2 billion in 2030.

Conclusions: Significant costs of arthritis through lost PLYS are incurred by individuals and government. The effectiveness of arthritis interventions should be judged not only on healthcare use but quality of life and economic wellbeing.
\end{abstract}

Keywords: Arthritis, Indirect costs, Income, Welfare payments, Taxation, GDP, Labour force participation, Microsimulation, Arthritis management

\footnotetext{
* Correspondence:

michelle.cunich@sydney.edu.au; http://www.sydney.edu.au

${ }^{2}$ The Boden Institute of Obesity, Nutrition, Exercise and Eating Disorders,

Charles Perkins Centre, The University of Sydney, Sydney, NSW 2006, Australia

Full list of author information is available at the end of the article
}

(c) The Author(s). 2018 Open Access This article is distributed under the terms of the Creative Commons Attribution 4.0 International License (http://creativecommons.org/licenses/by/4.0/), which permits unrestricted use, distribution, and reproduction in any medium, provided you give appropriate credit to the original author(s) and the source, provide a link to the Creative Commons license, and indicate if changes were made. The Creative Commons Public Domain Dedication waiver (http://creativecommons.org/publicdomain/zero/1.0/) applies to the data made available in this article, unless otherwise stated. 


\section{Background}

The latest Global Burden of Disease Study (2015) estimated there were 538 million Years Lived with Disability (YLDs) globally due to acute and chronic diseases and injuries in 1990, which increased to 764.8 million in 2013 due to population growth and ageing (42\% increase) [1]. Musculoskeletal disorders were a major category of chronic disease contributing to the increase in YLDs. YLDs for rheumatoid arthritis (RA) increased by $56.8 \%$ and for osteoarthritis (OA) by $75.4 \%$ between 1990 and 2013. While YLDs and other measures of disease burden are useful for evaluating and setting health policy, the indirect costs of chronic diseases are also important, and not only for health policy but related policy areas e.g. employment, finance and social security. Together, these measures provide vital information for modern governments in their pursuit of cross-portfolio solutions to complex health and social issues [2-4].

Current lost labour force participation due to arthritis - where 'arthritis' refers to a number of different conditions leading to inflamed or damaged joints, with the main conditions for people aged 45-64 years being OA and RA [5] - will impact on the future capacity of patients to maintain an adequate standard of living [6] and future governments to have sufficient revenue from which to fund the healthcare needed by the ageing population [2, 3]. Many governments are seeking new ways to make efficiency gains because the pool of workers is diminishing due to low fertility rates and population ageing [2]. Thus there is an urgency to calculate the indirect costs of chronic diseases for individuals and the government. It is widely acknowledged that investing in health contributes to the objectives of "smart, sustainable and inclusive growth" [4].

The direct costs of arthritis are substantial and rising. The main driver for these costs is the increasing prevalence of arthritis with ageing. In Australia, there are 3.9 million people with arthritis and this population is projected to grow to 5.4 million by 2030. Arthritis currently costs the health system $\$ 5.5$ billion and these costs are projected to grow to $\$ 7.6$ billion by 2030 [7].

However the indirect costs of arthritis are considered to be greater than the direct costs [7-9]. These extra costs are mostly due to lost productivity, with arthritis affecting an individual's ability to maintain employment due to pain and physical disability $[8,10]$; but also costs associated with the need for informal carers [11]. A recent study has shown that of the Australians aged 45-64 years who are out of the labour force due to ill-health, $13.3 \%$ were out because of arthritis in 2010 (45,000 people) [12]. Consequently, arthritis is the second most common chronic condition (after back problems) causing people to leave the labour force among those aged 45-64 years [12].
Commonwealth Treasury's Intergenerational Report (IGR) 2015 [2] highlights that population ageing and labour shortages are the main challenges facing the government in terms of budget sustainability. In response to these challenges, the Australian Government has sought to increase the Age Pension eligibility to 70 years by 2035 and implement other policies to encourage deferral of retirement. From 2012 to 2061, the proportion of the working-age group (15-64 years) who are aged 50-64 is projected to increase to between 27 and 30\% [13]. However this is also the age group from which $21 \%$ of men and $121 \%$ of women retire early due to own ill-health [14]. Thus the prevention and treatment of chronic conditions are crucial to keeping older workers in the labour force [15]. Importantly, a number of randomised controlled trials for the treatment of arthritis have demonstrated effectiveness in relation to increased labour force participation [8, 16]. Additionally, adjustments to relevant work-related factors can reduce the risk of work disability in people with arthritis (such as self-employment, modification of workstations, family support for the person with arthritis maintaining employment, reducing commuting difficulty, and increasing comfort for telling colleagues about arthritis) and thereby increase their employment status/duration. The aim of this study was to project the indirect costs of arthritis due to lost productive life years (PLYs) - defined as the number of people not in the labour force who would have been in the labour force were it not for their arthritis in a given year [12] - from 2015 to 2030 using a microsimulation model. We note that there has been a recent change in the United States' recommendations on cost-effectiveness analysis which highlights a move from excluding productivity costs to now including them $[17,18]$. This change suggests a specific need for the type of cost data that the current study presents.

\section{Methods}

A microsimulation model, Health\&WealthMOD2030, was used to project the indirect costs of arthritis for individuals and the government from 2015 to 2030. The data sources and statistical methods used to develop Health\&WealthMOD2030 are discussed in [19]. Figure 1 provides a graphical representation of the microsimulation model, Health\&WealthMOD2030, used in this study.

\section{Base population}

The base population of Health\&WealthMOD2030 consists of unit-record data (people aged 45-64) from the ABS Survey of Disability, Ageing and Carers (SDACs) 2003 and 2009 [20] - nationally representative household surveys. Personal (age, sex and family type), socioeconomic (education, labour force participation, income, receipt of welfare payments and type of payments) and health characteristics (main chronic condition) for each individual in the household were extracted. 


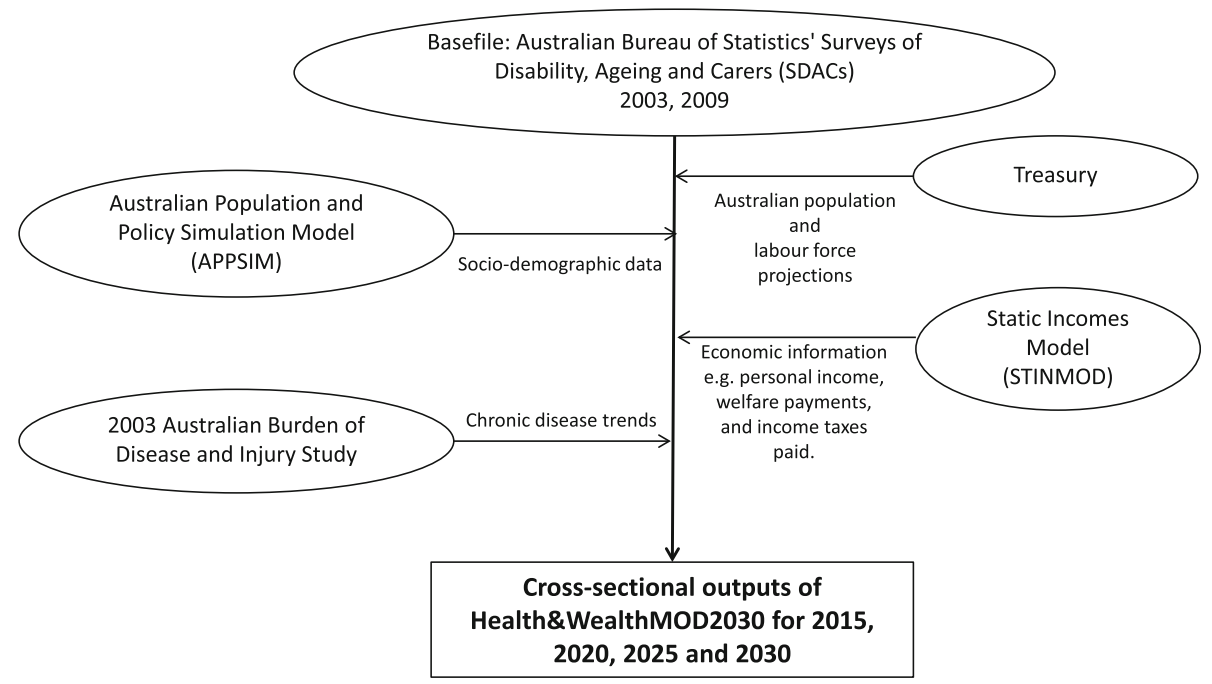

Fig. 1 Diagram of the Health\&WealthMOD2030 model

\section{Economic data}

The National Centre for Social and Economic Modelling's (NATSEM, University of Canberra) Static Incomes Model or STINMOD is the foremost microsimulation model of Australia's income tax and cash transfer (welfare) system [21]. Income, welfare, tax and wealth information from STINMOD's 2013 snapshot were imputed onto the base population of Health\&WealthMOD2030 by identifying individuals with similar characteristics on STINMOD and "donating" their economic information onto Health\&WealthMOD2030 using synthetic matching. Ten variables were used for synthetic matching: labour force status, income unit type, income quintile, receipt of Aged Pension, receipt of Disability Support Pension (DSP), sex, age group, hours of work per week, education and home ownership.

The economic data from STINMOD were indexed to match economic growth from 2013 to the projection years (2015, 2020, 2025 and 2030). Income and taxes were assumed to grow at a rate of $1 \%$ per annum in real terms and welfare payments to have no real growth - consistent with the Australian Government's policy of only increasing welfare payments in line with Consumer Price Index (CPI) growth.

\section{Population, labour force and chronic disease trends}

We used Commonwealth Treasury's population and work force projections from 2015 to 2030 (by five-year age group) in our model. We applied the projected age-sex specific distributions of other socio-demographic variables (education, income unit, home ownership and receipt of Disability Support Payments, DSP) from a second NATSEM microsimulation model, the Australian
Population and Policy Simulation Model (APPSIM) [22], in our modelling.

The chronic disease trends used in the model were the same as the trends in chronic condition incidence used in Begg et al.'s (2008) 2003 Australian Burden of Disease and Injury Study [23].

\section{Reweighting}

The SDACs 2003 and 2009 were reweighted separately using the ABS reweighting algorithm GREGWT [24] so as to account for demographic, labour force, disease prevalence and other changes between the survey years (2003 and 2009) and the projection years.

Use of SDACs 2003 and 2009 were approved by the ABS Microdata Review Panel.

\section{Lost productive life years (PLYs) due to arthritis}

All SDAC respondents who indicated (a) they were not in the labour force due to their 'own ill-health or disability', and (b) nominated their main health condition to be "arthritis and related disorders" (ICD10 code M00-19) were considered to have lost PLYs due to arthritis. Severity of arthritis is not collected in the SDACs although it is likely that those who are out of the labour force due to their condition have more severe arthritis.

\section{Indirect costs}

The indirect costs of arthritis through lost PLYs consisted of lost income, extra welfare payments, and lost taxation revenue. Personal income consisted of earnings, income from other sources producing a return, and welfare payments. Relevant welfare payments were: Disability Support Pension (DSP), Newstart Allowance, 
Carer Payment, and Family Tax Benefit (http://www.humanservices.gov.au). We note that the incremental welfare costs associated with reduced labour force participation for people with arthritis (versus those without) are most likely the costs of the DSP. The taxes paid by individuals included personal income tax and the Medicare levy.

We calculated the impact of arthritis on GDP in each year using projections and methods for estimating GDP and the impact of the work force from the Commonwealth Treasury [25].

\section{Statistical analysis}

We present a summary of the number of people with and without lost PLYs due to arthritis, and the mean (standard deviation) and median income, welfare payments and taxes paid per week by people aged 45-64 years in 2015, 2020, 2025 and 2030. All figures are expressed in real 2013 Australian dollars (AU\$) (that is, adjusted for changes due to inflation [CPI] over time).

A quantile regression model for median weekly income with age, sex and education as explanatory variables was used to estimate the difference between the income of people with lost PLYs due to arthritis versus full-time workers without arthritis in 2015, 2020, 2025 and 2030. Similar models for median weekly welfare payments and median weekly taxes were also estimated.

The national costs of arthritis through people aged 45-64 years exiting the labour force were projected from 2015 to 2030. The total income loss at a national level were estimated based on the differences between the income of those with lost PLYs due to arthritis and the income of those in full-time work with no arthritis and the income of those in part-time work with no arthritis and their probabilities of being in full-time, part-time work or unemployed if they did not have arthritis. 95\% Confidence Intervals (CIs) were generated for national income, welfare payments and taxes using bootstrapping with 1000 replications for each year.

The statistical analysis was conducted in SAS V9.4 (SAS Institute Inc., Cary, NC, USA), and all statistical tests were two-sided with a $5 \%$ level of significance.

\section{Results}

Among the 5,712,000 people aged 45-64 years in 2015, it was estimated that $54,000(0.9 \%)$ were out of the labour force due to arthritis; 307,000 (5.2\%) were working full-time with arthritis; 186,000 (3.1\%) were working part-time with arthritis; 2,912,000 (49\%) were working full-time without arthritis; and 1,032000 (17.4\%) were working part-time without arthritis (Table 1).

Those who were out of the labour force due to arthritis received an estimated $\$ 321.87$ in median income per week in 2015, which is only a quarter of the median income of full-time workers without arthritis (AU\$1308.88 per week) (Table 1). Those not in the labour force due to arthritis also received median welfare payments of AU\$311.67 per week (Table 1).

By 2030, the older working-age population was projected to be $6,843,000$ and consisted of 61,000 people with lost PLYs due to arthritis, 379,000 working full-time with arthritis, 236,000 working part-time with arthritis; $3,600,000$ working full-time without arthritis, and $1,340,000$ working part-time without arthritis. Those with lost PLYs due to arthritis were projected to receive AU\$352.05 per week in median income and AU\$311.67 per week in median welfare payments in 2030 (Table 1, last column).

Compared to those in full-time employment without arthritis (adjusted for age, sex and education), people out of the labour force due to arthritis were estimated to receive AU\$706.12 (95\%CI: AU\$606.23- AU\$743.17) less per week in median income in 2015 (Table 2). They also received significantly more in welfare payments (an extra AU\$311.67 per week, 95\%CI: AU\$310.99- AU\$413.50) and pay less in taxes (AU\$171.20 per week, 95\% CI: AU\$150.77- AU\$188.20) compared to full-time workers without arthritis. The differences in median weekly income, welfare payments and taxation between those with lost PLYs due to arthritis and full-time workers without arthritis were also estimated for 2030 (Table 2, last two columns). Lost income as a result of being out of the labour force due to arthritis was projected to increase from AU\$706.12 per week in 2015 (95\%CI: AU\$606.23- AU\$743.17) to AU\$970.96 per week in 2030 (95\% CI: AU\$920.52- AU\$1034.92) in real terms (compared to those working full-time without arthritis). People with lost PLYs due to arthritis paid an estimated AU\$171.20 per week (95\% CI: AU\$150.77- AU\$188.20) less in income taxes than those working full-time without arthritis in 2015, increasing to AU\$234.79 per week (95\% CI: AU\$205.48- AU\$243.53) in 2030.

The national impact of arthritis through lost PLYs consists of an estimated \$1516 million (95\%CI: AU\$1222 million- AU\$1725 million) in lost income in 2015, increasing to AU\$2406 million (95\%CI: AU\$2012 millionAU $\$ 2826$ million) in 2030 (i.e. a 59\% increase in lost income for this period) mainly due to ageing. Additional welfare payments paid as a result of people leaving the labour force because of arthritis were projected to increase by $13 \%$ over the period, from AU $\$ 847$ million $(95 \% \mathrm{CI}$ : AU\$732 million to AU\$1162 million) in 2015 to $\$ 959$ million (95\%CI: \$ AU823 million- AU\$990 million) in 2030 (Table 3). Finally, lost annual taxation revenue was projected to increase by $56 \%$ in real terms, from AU $\$ 352$ million (95\%CI: AU\$279 million- AU\$420 million) in 2015 to AU\$549 million (95\%CI: AU\$422 million- AU\$615 million) in 2030. 


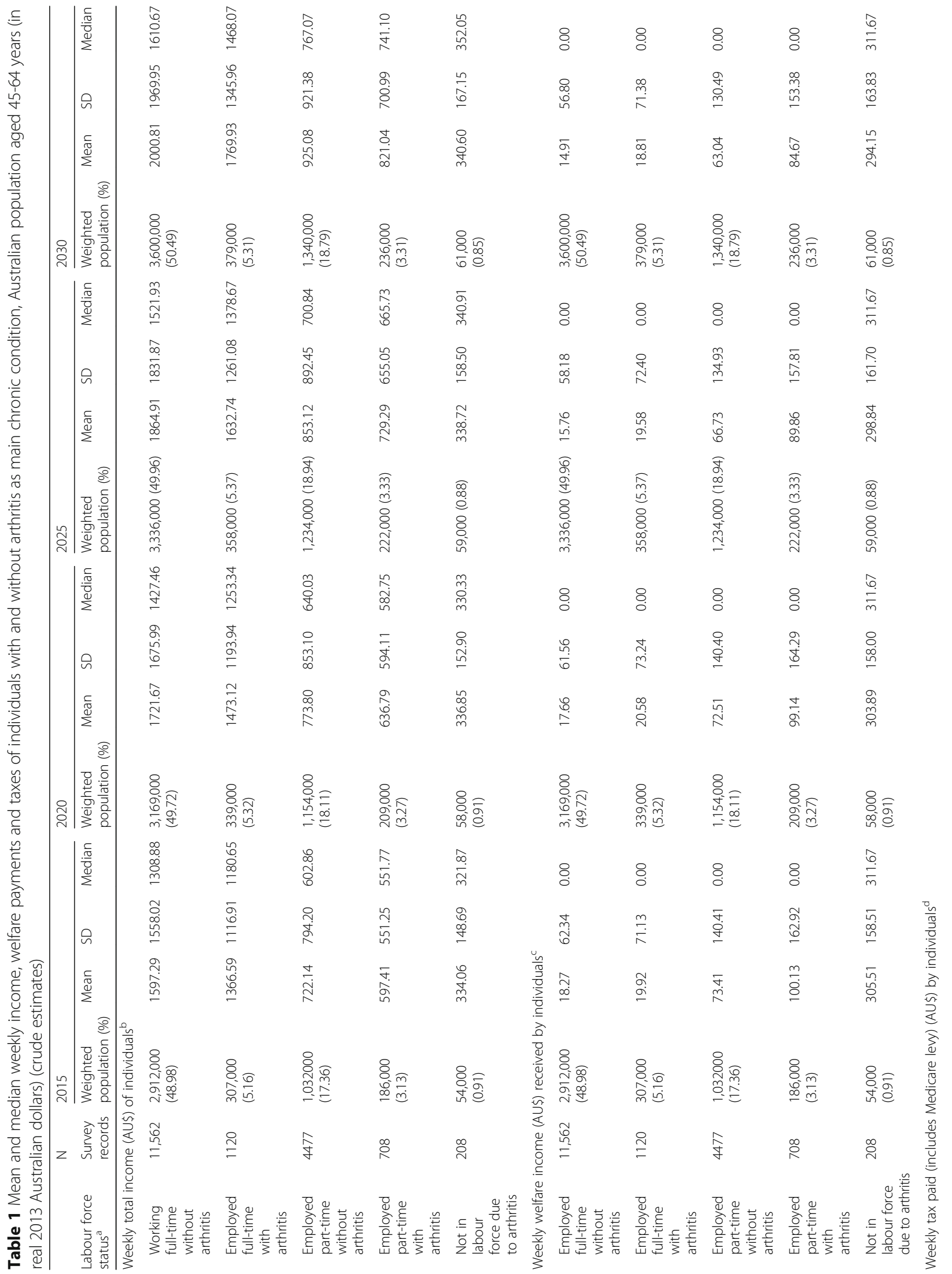




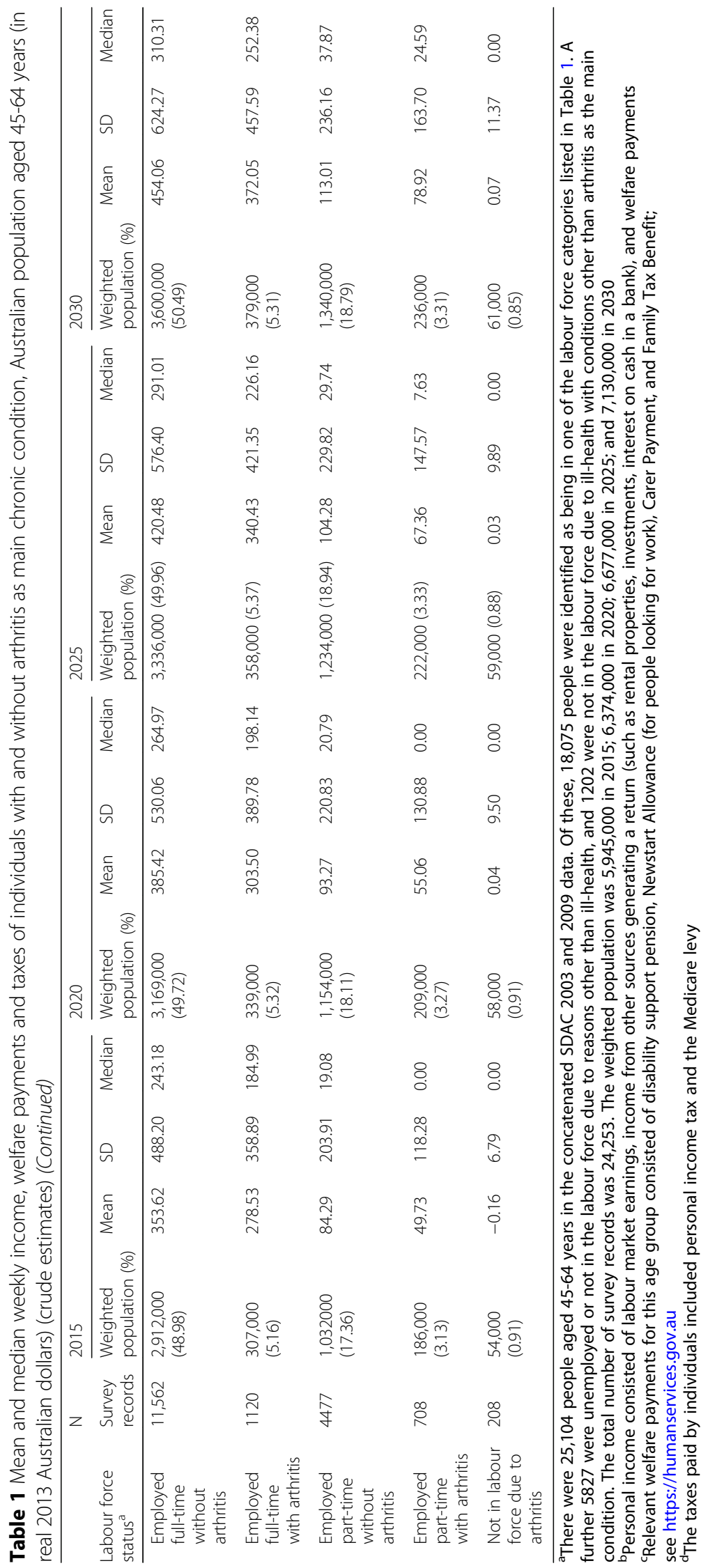


Table 2 Differences in median weekly income, welfare payments and taxes between older workers with lost PLYS due to arthritis and those employed full time without arthritis (adjusted for age, sex and education), Australian population aged 45-64 years (in real 2013 Australian dollars)

\begin{tabular}{|c|c|c|c|c|c|c|c|c|}
\hline \multirow[b]{2}{*}{ Labour force status } & \multicolumn{2}{|l|}{2015} & \multicolumn{2}{|l|}{2020} & \multicolumn{2}{|l|}{2025} & \multicolumn{2}{|l|}{2030} \\
\hline & \$ difference & $95 \% \mathrm{Cl}$ & $\$$ difference & $95 \% \mathrm{Cl}$ & $\$$ difference & $95 \% \mathrm{Cl}$ & \$ difference & $95 \% \mathrm{Cl}$ \\
\hline \multicolumn{9}{|c|}{ Weekly total income (AU\$) of individuals } \\
\hline $\begin{array}{l}\text { Employed full-time } \\
\text { without arthritis }\end{array}$ & \multicolumn{8}{|c|}{ Reference group } \\
\hline $\begin{array}{l}\text { Employed full-time } \\
\text { with arthritis }\end{array}$ & -25.18 & $(-76.50,31.50)$ & -24.80 & $(-76.67,41.52)$ & -18.43 & $(-83.35,33.48)$ & -27.61 & $(-91.66,36.61)$ \\
\hline $\begin{array}{l}\text { Employed part-time } \\
\text { without arthritis }\end{array}$ & $-565.61^{*}$ & $\begin{array}{l}(-597.42,- \\
534.83)\end{array}$ & $-609.04^{*}$ & $\begin{array}{l}(-645.23,- \\
571.85)\end{array}$ & $-652.58^{*}$ & $\begin{array}{l}(-687.79,- \\
619.42)\end{array}$ & $-698.11^{*}$ & $\begin{array}{l}(-726.50,- \\
658.14)\end{array}$ \\
\hline $\begin{array}{l}\text { Employed part-time } \\
\text { with arthritis }\end{array}$ & $-578.81^{*}$ & $\begin{array}{l}(-642.87,- \\
521.67)\end{array}$ & $-635.00^{*}$ & $\begin{array}{l}(-693.26,- \\
553.52)\end{array}$ & $-652.09^{*}$ & $\begin{array}{l}(-738.18,- \\
567.82)\end{array}$ & $-684.46^{*}$ & $\begin{array}{l}(-744.36,- \\
617.03)\end{array}$ \\
\hline $\begin{array}{l}\text { Not in labour force } \\
\text { due to arthritis }\end{array}$ & $-706.12^{*}$ & $\begin{array}{l}(-743.17,- \\
606.23)\end{array}$ & $-762.30^{*}$ & $\begin{array}{l}(-808.81,- \\
664.20)\end{array}$ & $-873.26^{*}$ & $\begin{array}{l}(-923.61,- \\
815.25)\end{array}$ & $-970.96^{*}$ & $\begin{array}{l}(-1034.92,- \\
920.52)\end{array}$ \\
\hline \multicolumn{9}{|c|}{ Weekly welfare income (AU\$) received by individuals } \\
\hline $\begin{array}{l}\text { Employed full-time } \\
\text { without arthritis }\end{array}$ & \multicolumn{8}{|c|}{ Reference group } \\
\hline $\begin{array}{l}\text { Employed full-time } \\
\text { with arthritis }\end{array}$ & 0.00 & $(0,0)$ & 0.00 & $(0,0)$ & 0.00 & $(0,0)$ & 0.00 & $(0,0)$ \\
\hline $\begin{array}{l}\text { Employed part-time } \\
\text { without arthritis }\end{array}$ & 0.00 & $(0,0)$ & 0.00 & $(0,0)$ & 0.00 & $(0,0)$ & 0.00 & $(0,0)$ \\
\hline $\begin{array}{l}\text { Employed part-time } \\
\text { with arthritis }\end{array}$ & 0.00 & $(0,5.75)$ & 0.00 & $(0,5.75)$ & 0.00 & $(0,0)$ & 0.00 & $(0,0)$ \\
\hline $\begin{array}{l}\text { Not in labour force } \\
\text { due to arthritis }\end{array}$ & $311.67^{*}$ & $(310.99,413.50)$ & $311.67^{*}$ & $(301.14,413.50)$ & $311.67^{*}$ & $(311.67,413.50)$ & $311.67^{*}$ & $(311.67,396.16)$ \\
\hline \multicolumn{9}{|c|}{ Weekly tax paid (includes Medicare levy) (AU\$) by individuals } \\
\hline $\begin{array}{l}\text { Employed full-time } \\
\text { without arthritis }\end{array}$ & \multicolumn{8}{|c|}{ Reference group } \\
\hline $\begin{array}{l}\text { Employed full-time } \\
\text { with arthritis }\end{array}$ & $-26.31^{*}$ & $(-44.46,-3.75)$ & $-22.73^{*}$ & $(-46.68,-3.02)$ & -23.56 & $(-40.13,1.91)$ & -17.17 & $(-38.82,5.48)$ \\
\hline $\begin{array}{l}\text { Employed part-time } \\
\text { without arthritis }\end{array}$ & $-158.54^{*}$ & $\begin{array}{l}(-166.71,- \\
148.13)\end{array}$ & $-172.76^{*}$ & $\begin{array}{l}(-182.94,- \\
161.71)\end{array}$ & $-195.21^{*}$ & $\begin{array}{l}(-207.55,- \\
185.22)\end{array}$ & $-208.60^{*}$ & $\begin{array}{l}(-221.35,- \\
198.15)\end{array}$ \\
\hline $\begin{array}{l}\text { Employed part-time } \\
\text { with arthritis }\end{array}$ & $-158.54^{*}$ & $\begin{array}{l}(-165.99,- \\
145.28)\end{array}$ & $-172.76^{*}$ & $\begin{array}{l}(-182.76,- \\
157.18)\end{array}$ & $-184.50^{*}$ & $\begin{array}{l}(-202.18,- \\
163.50)\end{array}$ & $-193.13^{*}$ & $\begin{array}{l}(-215.50,- \\
177.55)\end{array}$ \\
\hline $\begin{array}{l}\text { Not in labour force } \\
\text { due to arthritis }\end{array}$ & $-171.20^{*}$ & $\begin{array}{l}(-188.20,- \\
150.77)\end{array}$ & $-180.64^{*}$ & $\begin{array}{l}(-200.50,- \\
164.44)\end{array}$ & $-210.77^{*}$ & $\begin{array}{l}(-221.79,- \\
190.51)\end{array}$ & $-234.80^{*}$ & $(-243.53,-205.48)$ \\
\hline
\end{tabular}

${ }^{*} p$-value $<0.05$

Table 3 National costs of lost workers (full- and part-time) due to arthritis per year (in real 2013 Australian dollars, millions)

\begin{tabular}{|c|c|c|c|c|c|c|c|c|}
\hline \multirow[b]{2}{*}{ Cost } & \multicolumn{2}{|l|}{2015} & \multicolumn{2}{|l|}{2020} & \multicolumn{2}{|l|}{2025} & \multicolumn{2}{|l|}{2030} \\
\hline & \$ impact & $95 \% \mathrm{Cl}$ & \$ impact & $95 \% \mathrm{Cl}$ & \$ impact & $95 \% \mathrm{Cl}$ & $\$$ impact & $95 \% \mathrm{Cl}$ \\
\hline Lost income & 1516 & $(1222 ; 1725)$ & 1756 & $(1429 ; 2019)$ & 2086 & $(1739 ; 2433)$ & 2406 & $(2012 ; 2826)$ \\
\hline Extra welfare payments & 847 & $(732 ; 1162)$ & 912 & $(782 ; 1244)$ & 933 & $(548 ; 1261)$ & 959 & $(823 ; 990)$ \\
\hline Lost tax revenue & 352 & $(279 ; 420)$ & 394 & $(321 ; 476)$ & 473 & $(383 ; 548)$ & 549 & $(422 ; 615)$ \\
\hline
\end{tabular}

Lost workers per year:

Of the 54,000 people out of the labour force due to arthritis in 2015 , it is projected $39,000(71.68 \%)$ move into full-time employment and 14,000 ( $25.40 \%)$ move into part-time employment (the residual 1000 remain in unemployment)

Of the 58,000 people out of the labour force due to arthritis in 2020 , it is projected $41,000(71.46 \%)$ move into full-time employment and 15,000 ( $26.02 \%$ ) move into part-time employment (the residual 2000 remain in unemployment)

Of the 59,000 people out of the labour force due to arthritis in 2025 , it is projected $42,000(71.24 \%)$ move into full-time employment and 16,000 ( $26.37 \%$ ) move into part-time employment (the residual 1000 remain in unemployment)

Of the 61,000 people out of the labour force due to arthritis in 2030 , it is projected 43,000 (71.17\%) move into full-time employment and 16,000 (26.49\%) move into part-time employment (the residual 2000 remain in unemployment) 
Table 4 Lost GDP owing to missing workers aged 45-64 years due to arthritis, 2015-2030 (in real 2013 Australian dollars, millions) ${ }^{a}$

\begin{tabular}{|c|c|c|c|c|}
\hline & 2015 & 2020 & 2025 & 2030 \\
\hline Projected GDP & $\$ 1,483,861$ & $\$ 1,678,852$ & $\$ 1,899,467$ & $\$ 2,149,073$ \\
\hline Lost GDP owing to missing workers due to arthritis* & $\$ 6208$ & $\$ 6852$ & $\$ 7535$ & $\$ 8191$ \\
\hline Potential \% gain in total GDP if able to keep missing workers due to arthritis in the labour force & 0.42 & 0.41 & 0.40 & 0.38 \\
\hline
\end{tabular}

Impacts are based on projections of 53,000,56,000, 58,000 and 59,000 missing workers (full-time and part-time) due to arthritis in 2015, 2020, 2025 and 2030, respectively

We calculated the GDP losses attributable to older workers leaving the labour force because of arthritis to reach AU $\$ 6.2$ billion, AU $\$ 6.8$ billion, AU\$7.5 billion, and AU\$8.2 billion in 2015, 2020, 2025 and 2030, respectively (Table 4). If those people were able to undertake arthritis management that kept them in the work force then we predict a potential gain in GDP of $0.4 \%$ per year.

\section{Discussion}

The study projected that 54,000 people aged 45-64 years have lost PLYs due to arthritis in 2015, increasing to 61,000 in 2030 - a 13\% increase. The national impacts of lost PLYs due to arthritis consisted of a 59\% increase in lost income, which grew faster than the $13 \%$ increase in welfare payments due to the indexation of welfare payments being less than expected wages growth; and a $32 \%$ increase in lost GDP. The projection of long-term costs of arthritis, and the calculation of welfare payments and lost taxes are new contributions to the literature. These costs are in addition to the substantial health (direct) costs of arthritis. It is estimated that in the USA, $\$ 185.5$ billion in annual insurer expenditures are attributable to medical care for patients with OA [26].

There are some limitations to the study. One is that the study findings are based on SDAC respondents self-reporting work status and chronic diseases; although self-reported work status and health are considered to be valid measures for costing studies [27, 28]. Another is that the study focuses on measuring productivity as labour force participation and does not consider other forms such as presenteeism and absenteeism.

The main benefit of using large-scale microsimulation models (such as Health\&WealthMOD2030) is that they are based on micro data from national surveys conducted by the Australian Bureau of Statistics and therefore can be used to examine the impact of social policy changes on particular subgroups or demographics [29]. The models emulate the heterogeneity in the population due to the base population (and trends) being derived from a large household survey. Other benefits are that microsimulation models can be developed in such a way as to reproduce the complexity of policy arrangements, transfers and settings and consequently can be used to predict the outcomes of changes in policy using "what if" scenarios [30]. Thus Health\&WealthMOD2030 can be used to calculate the impacts of effective interventions to prevent or delay chronic diseases (such as non-surgical management of knee OA [8]) on potential cost savings for individuals and the government.

A number of randomised controlled trials for arthritis treatment have demonstrated effectiveness in terms of increased labour force participation [31]. Additionally, Lacaille et al. (2004) found that modifying work-related factors that increase the risk of work disability in people with arthritis (such as options for self-employment, workstation modification, work importance, family support towards employment, commuting difficulty, and comfort telling colleagues about arthritis) can increase employment [32]. In Australia, self-managed interventions to overcome workplace challenges associated with chronic pain have shown effectiveness. These results suggest that the government could achieve cost savings if effective arthritis management in workers occurred prior to their ill-health dictating withdrawal from the labour force, provided the costs to prevent arthritis outweigh the losses in indirect costs. In Australia, there are RCTs of self-management interventions to help overcome workplace challenges associated with chronic pain (such as musculoskeletal pain and arthritis) which have demonstrated effectiveness; for example, the 'ADAPT' for work-related pain program [33]. ADAPT is an intensive cognitive-behavioural pain management program, run by the Pain Management and Research Centre at the University of Sydney and Royal North Shore Hospital (http://sydney.edu.au/medicine/pmri/patient-services/resources/index.php), with a key focus on assisting people to better manage their pain and, in turn, their engagement with the work place [34]. The current study involved modelling the impact of arthritis on PLYs within the current treatment regimes. Future work could assess the likely impact of specific interventions that change the status quo and/or business as usual treatment for arthritis.

Quality of life is the most common measure of the benefits (or health outcomes) for patients in cost-effectiveness studies of health interventions. However, the results of the present study suggest that, not only would the amount of healthcare resources consumed by patients (direct medical costs) be important components of cost-effectiveness studies but also the indirect costs such as changes in labour market participation due to illness. The focus of 
this paper has been on quantifying the magnitude of the indirect costs of arthritis through lost labour force participation. We would also maintain that these additional costs are important considerations for policymakers in determining appropriate allocations of resources in health, social security, employment and other portfolios. The sentiments expressed in this paper are consistent with the recent change in the United States' recommendations on cost-effectiveness analysis which emphasises a move away from excluding (or ignoring) productivity costs to now including them in analysis $[17,18]$. Thus there is a particular need for the type of cost inputs that the current study presented.

\section{Conclusions}

Until recently, public policy has focused on economic incentives to increase labour force participation. However, as chronic disease is a key barrier to labour force participation in older workers, with arthritis being one of the diseases having the greatest impact on work capacity, more investment in health interventions to address chronic diseases are also needed.

\section{Funding}

The development of the microsimulation model used in this study, Health\&WealthMOD2030, is funded by the Australian Research Council (under grant LP100100158), and Pfizer Australia is a partner to the grant. All authors are independent from the funding sources, and the funding sources (including Pfizer Australia) played no part in the research design, undertaking of the analysis, formulation or interpretation of the results, decision to publish the research findings, nor any other part of the research process

MP is funded by Fellowships from the National Health and Medical Research Council of Australia and the Sydney Medical Foundation.

\section{Availability of data and materials}

The data used in this study are from Health\&WealthMOD2030, a microsimulation model constructed by the authors from the Survey of Disability, Ageing and Carers (SDACS) 2003 and 2009, STINMOD, APPSIM, population and labour force growth data from Treasury and disease trends data from the 2003 Australian Burden of Disease and Injury Study. The SDACs 2003 and 2009 are publicly available through the Australian Bureau of Statistics. Enquiries regarding access to other data sets and Health\&WealthMOD2030 should be directed to Professor Deborah Schofield, deborah.schofield@mq.edu.au.

\section{Authors' contributions}

DS conceived and led the study. DS, RT, MP made substantial contributions to study conception and design. DS, RS, RT made substantial contributions to acquisition of data. DS, MC, RS, JLV, SK made substantial contributions to analysis and interpretation of data. DS, MC, RS, RT, JLV, SK, MP were responsible for drafting the article or revising it critically for important intellectual content. DS and MC wrote the first draft of the article. RS developed Health\&WealthMOD2030. RT contributed to model design and reweighting of data. JLV worked on the chronic conditions trends data. JLV and MP provided expert opinion on the prevalence of chronic conditions and trends. All authors gave final approval of the version of the article to be published.

\section{Ethics approval and consent to participate}

Use of SDACs 2003 and 2009 were approved by the ABS Microdata Review Panel. Data used in this study are de-identified data, and survey respondents have consented to participating in the national surveys.

The data used in this study are from Health\&WealthMOD2030, a microsimulation model assembled by the authors from the SDACs 2003 and 2009, STINMOD,
APPSIM, population and labour force growth data from Treasury and disease trends data from the 2003 Australian Burden of Disease and Injury Study. The SDACs 2003 and 2009 are openly available through the Australian Bureau of Statistics.

\section{Competing interests}

The authors declare that they have no competing interests.

\section{Publisher's Note}

Springer Nature remains neutral with regard to jurisdictional claims in published maps and institutional affiliations.

\section{Author details}

${ }^{1}$ GenIMPACT: Centre for Economic Impacts of Genomic Medicine, Department of Economics, Faculty of Business and Economics, Macquarie University, Sydney, NSW 2107, Australia. ${ }^{2}$ The Boden Institute of Obesity, Nutrition, Exercise and Eating Disorders, Charles Perkins Centre, The University of Sydney, Sydney, NSW 2006, Australia. ${ }^{3}$ National Centre for Social and Economic Modelling, University of Canberra, Canberra, ACT, Australia. ${ }^{4}$ School of Medicine, Griffith University, Gold Coast, QLD, Australia. ${ }^{5}$ University Centre for Rural Health, School of Public Health, The University of Sydney, Lismore, NSW, Australia. ${ }^{6}$ Cancer Council NSW, Woolloomooloo, NSW 2011, Australia.

Received: 29 August 2017 Accepted: 25 April 2018

Published online: 24 May 2018

\section{References}

1. Global Burden of Disease Study 2013 Collaborators. Global, regional, and national incidence, prevalence, and years lived with disability for 301 acute and chronic diseases and injuries in 188 countries, 1990-2013: a systematic analysis for the global burden of disease study 2013. Lancet. 2015;386(9995): 743-800.

2. Commonwealth of Australia. 2015 intergenerational report: Australia in 2055. Canberra: The Commonwealth of Australia; 2015.

3. Masters R AE, Collins B, Cookson C, Capewell S. Return on investment of public health interventions: a systematic review. J Epidemiol Community Health 2017;0:1-8. doi:https://doi.org/10.1136/jech-2016-208141.

4. Bere RC, Bucerzan I. Cluster analysis on cohesion policy towards Europe 2020 strategy for smart, sustainable and inclusive growth. Rom Stat Rev. 2015:63(4):95-111. December

5. Access Economics Pty Ltd for Arthritis Australia. Painful realities: the economic impact of arthritis in Australia. Adelaide: Arthritis Australia; 2007.

6. Schofield DJ, Callander EJ, Shrestha RN, Percival R, Kelly SJ, Passey ME. Labour force participation and the influence of having arthritis on financial status. Rheumatol Int. 2015;35(7):1175-81.

7. Ackerman IA, Bohensky MA, Pratt C, Gorelik A, Liew D. (Melbourne EpiCentre the University of Melbourne). Counting the cost: part 1 healthcare costs - the current and future burden of arthritis. Sydney: Arthritis Australia; 2016

8. Schofield D, Shrestha R, Cunich M. Counting the cost: part 2 economic costs. Sydney: Arthritis Australia; 2016.

9. Arthritis Research Network. State of musculoskeletal health 2017: arthritis \& other musculoskeletal conditions in numbers. Chesterfield: Arthritis Research UK. p. 2017

10. Schofield D, Shrestha RN, Cunich MM, Tanton R, Veerman L, Kelly SJ, et al. Economic costs of chronic disease through lost productive life years (PLYs) among Australians aged 45-64 years from 2015 to 2030: results from a microsimulation model, health\&WealthMOD2030. BMJ Open. 2016;6: e011151. https://doi.org/10.1136/bmjopen-2016-011151.

11. Schofield D, Cunich M, Shrestha R, Passey M, Veerman L. The impact of chronic conditions of care recipients on the labour force participation of informal carers in Australia: which conditions are associated with higher rates of non-participation in the labour force? BMC Public Health. 2014:14:561

12. Schofield D, Shrestha R, Cunich M, Tanton R, Kelly S, Veerman L, et al. Lost productive life years caused by chronic conditions in Australians aged 45-64 years, 2010-2030. Med J Aust. 2015;203(6):260. e1-6

13. Australian Bureau of Statistics. 32220 - population projections, Australia, 2012 (base) to 2101. Canberra: Australian Bureau of Statistics; 2013. 
14. Australian Bureau of Statistics. 6238.0 - retirement and retirement intentions, Australia, July 2016 to June 2017. Canbera: Australian Bureau of Statistics; 2017.

15. Australian Human Rights Commission. Willing to work: National Inquiry into employment discrimination against older Australians and Australians with disability, healthy ageing paper. Sydney: Australian Human Rights Commission; 2016.

16. Schofield D, Shrestha R, Cunich M, West S. Measuring labour productivity and the benefits of interventions for osteoarthritis. Sydney: Medicines Australia; 2016.

17. Roberts MS. The next chapter in cost-effectiveness analysis. JAMA. 2016; 316(10):1049-50.

18. Sanders GD, Neumann PJ, Basu A, Brock DW, Feeny D, Krahn M, et al. Recommendations for conduct, methodological practices, and reporting of cost-effectiveness analyses: second panel on cost-effectiveness in health and medicine. JAMA. 2016:316(10):1093-103.

19. Schofield D, Shrestha R, Kelly S, Veerman L, Tanton R, Passey M, et al. Health\&WealthMOD2030: a microsimulation model of the long term economic impacts of disease on the labour force participation of Australians aged 45-64 years old. Int J Microsimulation. 2014;7(2):94-118.

20. Australian Bureau of Statistics. Survey of disability, ageing and Carers 2009 cat. No. 4430.0. Canberra: Australian Bureau of Statistics; 2012.

21. Percival R, Abello A, Vu QN. STINMOD (static income model). In: Gupta A, Harding A, editors. Modelling our future: population ageing, health and aged care. Amsterdam: Elsevier B.V; 2007.

22. Keegan M, Kelly S. APPSIM - dynamic microsimulation modelling of social security and taxation. Canberra: National Centre for Social and Economic Modelling, University of Canberra; 2009.

23. Begg SJ, Vos T, Barker B, Stanley L, Lopez AD. Burden of disease and injury in Australia in the new millennium: measuring health loss from diseases, injuries and risk factors. Med J Aust. 2008;188(1):36-40.

24. Bell P. GREGWT and TABLE macros - users guide. Canberra: Australian Bureau of Statistics; 2000.

25. Commonwealth Treasury. Intergenerational report 2007. Canberra: Commonwealth of Australia; 2007.

26. Kotlarz H, Gunnarsson CL, Fang H, Rizzo JA. Insurer and out-of-pocket costs of osteoarthritis in the US: evidence from national survey data. Arthritis Rheum. 2009:60:3546-53.

27. Wannamethee G, Shaper AG. Self-assessment of health status and mortality in middle-aged British men. Int J Epidemiol. 1991;20(1):239-45.

28. Cai L, Kalb G. Health status and labour force participation: evidence from Australia. Health Econ. 2006;15(3):241-61.

29. Creedy J. Tax modelling. Econ Record. 2001;77(237):189-202.

30. Brown L, Harding A. Social Modelling and Public Policy: What is microsimulation modelling and how is it being used? "Its Not Just About the Dollars: Measuring and Reporting the Economic and Social Benefits of Standards under the Disability Discrimination Act" - a Forum held by the Disability Studies and Research Institute (DSaRI) in conjunction with the Social Relations of Disability Research Network (SRDRN) on 19 July 2002; University of Technology, Sydney: National Centre for Social and Economic Modelling (NATSEM), University of Canberra. Canberra: NATSEM; 2002.

31. Yelin E, Katz P, Lubeck D, Wanke L, Buatti M. Impact of Etanercept (ENBREL ${ }^{\oplus}$ ) on health care use and employment in early RA. Arthritis Rheum. 2001; 44(Supplement 9):152.

32. Lacaille D, Sheps S, Spinelli JJ, Chalmers A, Esdaile JM. Identification of modifiable work-related factors that influence the risk of work disability in rheumatoid arthritis. Arthritis Rheum. 2004;51(5):843-52.

33. Shaw W, Tveito T, Geehern-Lavoie M, Huang Y, Nicholas M, Reme S, et al. Adapting principles of chronic pain self-management to the workplace. Disabil Rehabil. 2012;34(8):694-703.

34. Shaw W, Bessen E, Pransky G, Boot C, Nicholas M, McLennan R, et al. Manage at work: a randomized, controlled trial of a self-management group intervention to overcome workplace challenges associated with chronic physical health conditions. BMC Public Health. 2014;14(1):1-11.

\section{Ready to submit your research? Choose BMC and benefit from:}

- fast, convenient online submission

- thorough peer review by experienced researchers in your field

- rapid publication on acceptance

- support for research data, including large and complex data types

- gold Open Access which fosters wider collaboration and increased citations

- maximum visibility for your research: over $100 \mathrm{M}$ website views per year

At BMC, research is always in progress.

Learn more biomedcentral.com/submissions 